\title{
INOVAÇÃO E PRODUÇÃO: ANÁLISE CONCEITUAL E EMPÍRICA DO CASO PAVIMENTAÇÃO COM ASFALTO
}

\author{
Antônio Ricardo Pimentel de Oliveira ${ }^{1}$ \\ Peter Rudolf SeidR \\ Waldimir Pirró y Longo ${ }^{3}$
}

\begin{abstract}
Resumo: $O$ trabalho visa verificar a existência de um sistema setorial de inovação e produção em pavimentação no Brasil, identificar disfunções ou lacunas neste sistema, e propor soluções para sua adequada estruturação. A pavimentação de rodovias é chave para o crescimento e competitividade do Brasil. A análise tem por suporte o conceito de sistemas de inovação, e por método, o estudo de caso, segundo a abordagem do Projeto ESSY europeu, específica aos casos setoriais. São relatados resultados referentes aos seguintes aspectos do setor: [1] conhecimento e processo de aprendizado; [2] suas empresas (firmas), organizaçōes não-empresariais, redes e instituições; [3] dinâmica setorial de longo prazo e coevolução; [4] políticas públicas; [5] fronteiras geográficas; e [6] desempenho internacional. A pesquisa indicou desafios, tanto para engenheiros rodoviários, quanto para gestores deste modal: o percentual de pavimentação atingido na malha rodoviária brasileira é modesto; ela apresenta excesso de tráfego e sobrecarga sobre seus pavimentos; e evidências apontam para práticas de dimensionamento defasadas do nível de solicitação aplicado nas rodovias. Verificou-se coexistirem: efeitos positivos decorrentes das políticas e ações no campo científico, tecnológico e da educação, gerando aprendizado e inovaçôes, assim como introdução de inovações pelas firmas; e as conseqüências ainda vigentes do enfraquecimento ocorrido nos órgãos rodoviários, que limitam o aproveitamento pleno das oportunidades de inovação.
\end{abstract}

Palavras-chave: asfalto, pavimentação, inovação, produção.

Abstract: The paper aims to verify the existence of a sectoral system of innovation and production in road building in Brazil, identifying dysfunctions or gaps, and proposing solutions for its appropriate structuring. The road building paving is a key activity for the growth and competitiveness of Brazil. The analysis is supported by the concept of innovation systems. The "case study" was the main way of researching here used, complemented by the European ESSY-Project method, suitable for sectoral studies. The results related to the following aspects are presented: [1] knowledge and learning process; [2] its companies (firms), nobusiness organizations, networks and institutions; [3] long term sectoral dynamics and (co)evolution; [4] public policies; [5] geographical frontiers; [6] and international performance. The research indicated a set of challenges for the road engineers as for the managers ahead the road system: the paving roads share reached by the Country is very modest; there is excessive traffic and overloading on the pavements; and evidences of standards that induce to calculate the pavements above the necessary resistance to support the applied level of charges in the Brazilian roads. It was also verified that coexist: the current positive effects of the policies and actions applied in the scientific, technological and education areas, generating learning and innovations, as well as introduction of innovations by the firms; and the weakness effects on the public departments ahead the roads, limiting to take advantage from the innovation opportunities.

Keywords: asphalt, paving, innovation, production.

Petrobras.

2 Universidade Federal do Rio de Janeiro - UFRJ.

3 Universidade Federal Fluminense - UFF (aposentado) 


\section{INTRODUÇÃO}

Nos países que apresentam plenos desenvolvimentos econômicos e sociais, a questão da logística configura-se como um dos fatores mais estratégicos. Comparaçōes internacionais apontam que o Brasil, nesse particular, apresenta excessivo viés na utilização de um tipo específico de modal - o rodoviário - que apresenta histórico de desenvolvimento insuficiente, assim como pouca expansão. Sua malha de rodovias embora extensa, ainda é pouco pavimentada se comparada com outros países mais desenvolvidos. Há também percepções no meio rodoviário que sugerem estar essa malha exposta a um regime de utilização e de desgaste talvez mais severo que as malhas européias e norte-americanas (Schroeder, 1996). Esse conjunto de fatores traz significativos efeitos que acabam por influir negativamente sobre o processo do desenvolvimento econômico. Há muitos municípios no País com insuficiente, e inadequada, infraestrutura de transporte, o que dificulta o escoamento da produção rural assim como o acesso das respectivas populações às facilidades urbanas existentes em suas regiōes ou em regiōes vizinhas.

A pavimentação de rodovias e sua manutenção requerem investimentos contínuos e elevados. Esses gastos são realizados, essencialmente, pelo governo federal e pelos estaduais, e em menor porte, pelos governos municipais. Os investimentos municipais em geral dependem dos níveis de arrecadação, sendo eles mais elevados naqueles municípios que são capitais dos Estados ou que sejam pólos de forte influência econômica regional, e por isso possuidores de maior grau de urbanização e infraestrutura de transporte.

Muito se tem questionado o desempenho da malha rodoviária nacional. Alguns aspectos, entretanto, condicionam o comportamento funcional dos pavimentos, tanto das rodovias federais e estaduais, quanto das rodovias urbanas e vicinais. A durabilidade deste modal tão utilizado no País depende do seu dimensionamento estrutural, dos materiais utilizados e da forma de combiná-los, do controle tecnológico realizado nas diversas fases do processo de construção e pavimentação das vias, etc. Como as condições referentes às demandas logísticas dos segmentos usuários não são estáticas, faz-se necessário também constante promoção de inovações seja para enfrentar questôes inéditas, seja para adequar as vias às condi- ções funcionais que são cambiantes ou para adotar soluçôes que foram eficazes em países ou em regióes consideradas como sendo referenciais tecnológicos válidos e confiáveis.

O presente trabalho tem por objetivo verificar a existência de um sistema setorial de inovação e produção em pavimentação com asfalto no Brasil, e identificar eventuais disfunçóes ou lacunas neste sistema, assim como propor soluções para sua adequada estruturação. A justificativa dessa investigação é o fato do modal rodoviário ser fator estratégico ao crescimento e competitividade das diversas regióes do Brasil. O referencial teórico utilizado na pesquisa é a conceituação econômica sobre sistemas de inovação. $\mathrm{O}$ estudo foi desenvolvido segundo a abordagem preconizada no Projeto ESSY europeu, que analisou os sistemas de inovação e produção dos seguintes setores: setor de serviços, o de software, o de equipamentos e serviços de telecomunicações, o de biotecnologia e fármacos, o de máquinas ferramentas, e de produtos químicos. (Malerba, 2002b). O referido Projeto será adiante detalhado.

\section{INOVAÇÃO E A ABORDAGEM SETORIAL}

O conceito econômico da inovação abrange cinco possíveis tipos de inovação: (1) a fabricação de novos bens; (2) novos métodos de produção; (3) a abertura de um novo mercado; (4) a utilização de novas matérias-prima (novas em si mesmas, ou que sejam oriundas de novas fontes de suprimento); e (5) nova forma de organização industrial, como por exemplo, a criação de um monopólio, ou inversamente, a "quebra" de um monopólio existente. (Schumpeter, 1934).

Inovações tecnológicas em produtos e processos, por outro lado, especificamente significam: (a) a efetiva introdução de produtos e processos tecnologicamente novos; ou (b) substanciais melhorias tecnológicas em produtos e processos já existentes. Uma inovação tecnológica em produto ou em processo só é considerada efetivamente implantada se tiver sido introduzida no mercado, no caso da inovação de produto, ou usada no processo de produção, caso seja uma inovação de processo. Inovaçôes tecnológicas, seja em produto ou em processo, envolvem uma série de atividades científicas, tecnológicas, organizacionais, financeiras e comerciais. (OCDE; 1997). 
A abordagem de sistemas de inovação (SIs) surgiu a partir da segunda metade da década de 1980 fundamentada nos trabalhos de Freeman (1987), Lundvall (1992), Nelson (1993) e Edquist (1997). Desde então o conceito se tornou largamente utilizado no âmbito acadêmico e também intensamente empregado como diretriz na proposição de políticas de inovação. Tal aderência se deve ao fato de que este conceito e abordagem auxiliam na identificação dos fatores determinantes que influenciam o desenvolvimento, difusão e uso das inovações. Inicialmente a principal ênfase desse desenvolvimento teórico eram os sistemas nacionais de inovação (Freeman 1987; Lundvall 1982; Nelson 1983). Posteriormente surgiram ramificações do conceito, como os sistemas setoriais de inovação (Breschi e Malerba, 1997; Carlson, 1995; Nelson e Mowery, 1999), e os sistemas regionais de inovação (Cooke, Gomez Uranga e Etxebarria, 1997; Braczyk, Cooke e Heidenreich, 1998 ; e Cooke, 2000).

Os SIs representam a reunião de diferentes tentativas de inserir o conteúdo da economia institucional na análise econômica de temas estreitamente vinculados à inovação, como: o fenômeno da mudança técnica, a "arquitetura" dos sistemas científicos, e a gênese da inovação tecnológica. (Amable, 2001). Dentre as diversas abordagens há as que buscam também analisar as consequiências da inovação no desempenho econômico das naçóes no longo prazo. Estudos semelhantes ao da presente investigação, envolvendo cadeias produtivas, e como torná-las eficazes e competitivas são feitos sob a ótica dos Sistemas Setoriais de Inovação e Produção (SSIPs). A abordagem por tais sistemas setoriais é propícia para análise de dois tipos de questôes. Um deles é o que trata das ações empreendedoras predominantemente aderentes ao determinismo tecnológico (exemplos: as definições de inovação da OCDE, acima, contidas no Manual de Oslo, ou as empregadas pelo Instituto Brasileiro de Geografia e Estatística - IBGE, na sua Pesquisa de Inovação Tecnológica - PINTEC). Outro tipo é aquele orientado à busca de como superar eventuais obstáculos institucionais, assim como superar certas condições históricas vigentes nos setores industriais, os quais obstruem o crescimento e competitividade dos setores (exemplo principal: a definição de inovação acima, segundo Schumpeter). Para isso, neles são consideradas as especificidades setoriais, o que envolve entender também as diferenças entre nações, pois estas não necessariamente estão em estágios de industrialização semelhantes, nem apresentam níveis de desenvolvimento tecnológico próximos. As estruturas dos setores industriais diferem entre si e, considerando um mesmo tipo de setor, elas podem, em certo grau, diferir de um país para outro. Existem também especificidades que caracterizam o arcabouço institucional de cada país, influenciando de maneira própria seus diversos setores industriais. Isso ocorre mesmo entre os países desenvolvidos, os quais embora estejam já intensamente industrializados, não necessariamente praticam o mesmo tipo de capitalismo.

Todas as vertentes de pesquisa que convergiriam no conceito dos SIs tiveram como ponto de partida comum saírem da concepção da inovação, como sendo ela algo de decisão relativamente individual, e independente do ambiente entorno em favor de outra concepção, que é a da inovação como decorrente de atores inseridos em diferentes redes e vivenciando variadas práticas institucionais.

Assim, dependendo da abordagem usada nesse tipo de estudo, o ambiente a considerar pode ter extensão maior ou menor. Em geral se deve partir das interações mínimas, aquelas que caracterizam o sistema segundo as ações dos protagonistas mais diretamente envolvidos com as especificidades técnicas do processo de inovação. A partir daí, num segundo estágio, adentra-se as consideraçóes sobre a vasta gama de influências, atuando no processo da inovação, e oriundas dos diversos agentes econômicos. A abordagem dos SI-s tem o mérito de permitir sair da exclusiva visão da mudança técnica (technical change), manifesta de maneira quase que autônoma do resto da economia, em prol da reintegração do processo da inovação dentro da economia e da sociedade. $\mathrm{O}$ conceito vivenciou certa notoriedade junto às instâncias econômicas dos países, e junto aos organismos internacionais, notadamente a OCDE e a Comissão Européia o utilizaram para orientar suas políticas de inovação. Ao longo da sua evolução o conceito de SIs cresceu sob influências variadas, de origem na economia e na sociologia: os estudos da mudança técnica; a teoria do crescimento; a teoria das organizações; a análise comparativa dos capitalismos; etc. (Amable, 2001). 


\section{METODOLOGIA}

Em termos gerais a investigação em curso está sendo conduzida através do método fenomenológico, buscando-se a descrição do setor examinado tal como ele é empiricamente observado. A abordagem empregada é qualitativa, através do estudo de caso, visto que a realidade setorial aqui examinada tende a ser construída socialmente. $\mathrm{Na}$ investigação se utilizou procedimentos distintos que se complementaram, como as pesquisas de natureza bibliográfica, documental, a pesquisa- participante e a pesquisa-ação, uma vez que um dos autores é um profissional da área. Esta última, a pesquisa-ação, dá ao trabalho um caráter também experimental - não no sentido laboratorial propriamente dito, e sim num sentido de "pesquisa de campo" sobre certos aspectos setoriais.

A investigação possui as seguintes características: o suporte conceitual através da noção de sistemas de inovação; a abordagem por "estudo de caso"; verificação da hipótese se existe, ou não, no Brasil, um sistema setorial de inovação e produção em pavimentação rodoviária com asfalto. Adicionalmente, quanto à abordagem, coleta e análise das evidências, busca-se no trabalho adaptar e utilizar a metodologia desenvolvida pelo Projeto-ESSY, a seguir descrita: ESSY Project - Sectoral Systems in Europe (innovation, competitiveness and growth).

O método do Projeto-ESSY analisa tanto as interações dos atores estreitamente vinculados às transformações técnicas do processo de inovação quanto trata do espectro mais amplo das influências exercidas pelos demais agentes econômicos e sociais. O Projeto envolveu dez grupos de pesquisa em sete países europeus, e analisou, entre 1999 e 2001, o setor de serviços (entre eles especialmente o serviço aeroportuário londrino), o de software, o de equipamentos e serviços de telecomunicaçôes, o de biotecnologia e fármacos, o de máquinas ferramentas, e também o setor de produtos químicos. As pesquisas foram coordenadas pelo pesquisador Franco Malerba, da Universidade de Bocconi, situada em Milão, na Itália. Este projeto visou fornecer um conjunto amplo de benefícios aos formuladores de políticas públicas, às firmas, às organizaçōes não empresariais e aos pesquisadores acadêmicos.

Os produtos visados foram: (a) entendimento profundo dos processos que são determinantes para obtenção e sustentação da inovação, para a vantagem competitiva nacional e para a liderança internacional - em relação à geração e difusão de conhecimento e de novas tecnologias no nível setorial; (b) melhor conhecimento sobre as diferenças setoriais, e o papel destas diferenças para o desenvolvimento econômico europeu; (c) profundo entendimento das interações e da coevolução, em termos específicos de cada setor, entre firmas e organizações não empresariais - tais como universidades, mercado de trabalho e organizações financeiras; (d) comparação explícita dos setores europeus examinados com seus equivalentes japoneses e americanos.

Esses produtos acima foram considerados aqueles capazes de permitir aos formuladores de políticas realizarem: (1) a definição de diferentes níveis de intervenção (no escopo regional, no nacional, ou no europeu); e (2) a definição de ferramentas apropriadas (infraestruturas, treinamentos, financiamentos de iniciativas de pesquisa e desenvolvimento, direitos de propriedade intelectual, proteção de mercado, formas de cooperação, alianças tecnológicas, etc.) para o crescimento e competitividade dos diferentes sistemas setoriais. (Malerba, 2002b).

\section{PAVIMENTAÇÃO COM ASFALTO}

Os setores analisados pelos europeus foram setores relativamente mais intensivos em tecnologia que o caso da pavimentação aqui estudado. Entretanto, não é prudente minimizar o valor estratégico da questão rodoviária, seja no contexto brasileiro em particular, ou seu valor geral para os países em vias de desenvolvimento. No setor aqui estudado foram identificados alguns "subsetores" internos ao sistema de inovação e produção que podem ser considerados estando simultaneamente presentes como partes de outros setores industriais específicos. Por exemplo, as firmas empreiteiras, as concessionárias, as projetistas e as firmas de consultoria, no setor de pavimentação rodoviária, também são partes do setor de construção civil; assim como as firmas fabricantes de usinas de asfalto e vibroacabadoras, estão presentes como segmentos do setor de máquinas e equipamentos; e há no setor de pavimentação um fornecedor de grande porte que, essencialmente, é uma empresa do setor de refino petrolífero, a Petrobras, detentora de várias refinarias produtoras de asfalto, e cujas instalações e dinâmica operacional aproximam-se do perfil da firmas do setor químico. 
No caso da pavimentação rodoviária, a investigação à semelhança do que foi realizado nas investigações européias do projeto ESSY, pretende entender o papel das organizações não empresarias (as "não-firmas", como universidades, institutos de pesquisa, agências, autarquias, associações, etc.) e o papel das demandas brasileiras sobre o setor, demandas essas com características e especificidades locais, e conseqüentemente entender como esses fatores afetam o processo de coevolução entre a tecnologia da pavimentação brasileira, a organização e estratégia das firmas dos diversos segmentos setoriais, e as práticas institucionais vigentes neste setor, no Brasil.

O estudo, analogamente ao preconizado no projeto ESSY, busca questionar as diversas características setoriais relevantesà inovação. Foram examinadas evidências sobre aspectos ligados ao chamado "determinismo tecnológico", e ao perfil geral das práticas institucionais do setor, aspectos esses considerados chaves para o crescimento e competitividade setorial. Através de evidências (pesquisa bibliográfica e documental, pesquisaação, pesquisa participante), preliminarmente foi levantado "o perfil da demanda setorial existente, e a qualidade do atendimento atual a esta demanda", e em seguida, foram investigados os seguintes tópicos: (i) Base de conbecimento e processo de aprendizado; (ii) Empresas (firmas), organizaçôes não-empresariais, redes e instituiçôes; (iii) Dinâmica setorial de longo prazo e processos coevolutivos; (iv) Políticas públicas; (v) Fronteiras geográficas; (vi) Desempenho internacional.

\section{REPRESENTAÇÃO SETORIAL NO BRASIL}

Para possibilitar interpretar as funções dos diferentes agentes setoriais, eles foram agrupados em seis grandes "blocos". O primeiro bloco (10 bloco) da representação setorial se refere aos atores responsáveis pelo fornecimento do asfalto propriamente dito. A concentração empresarial e a pulverização produtiva regional desse bloco é bem característica. Nele há uma empresa atuante, a Petrobras, com unidades produtoras de asfalto - "um conjunto de refinarias de petróleo pertencentes a essa única empresa”. A Petrobras atua desde a exploração do petróleo, até o seu refino final - etapa última esta na qual se produz o produto utilizado na pavimentação rodoviária, o asfalto. $\mathrm{O}$ segundo bloco (2 $2^{\circ}$ bloco $)$ da representação são os agentes que compram o asfalto da empresa produtora, e o vendem no mercado consumidor. Essas diversas empresas são as chamadas "distribuidoras". As distribuidoras de asfalto gradativamente ocuparam alguns nichos de produção, como a produção e a venda de emulsões de asfalto e, também, a produção e comercialização de asfaltos modificados por polímeros ou por elastômeros.

O terceiro bloco ( $\mathbf{3}^{\circ}$ bloco $)$ considerado no estudo é o que agrupa as diferentes firmas que estão mais diretamente ligadas às operaçôes de pavimentação. Devido seu grau de heterogeneidade, este terceiro bloco foi subdividido em quatro sub-blocos. O primeiro sub-bloco $\left(3^{A}\right)$ é o das empresas concessionárias de rodovias. Elas em geral estão também presentes no setor de engenharia civil, no segmento de construção "pesada", realizando obras rodoviárias. Tais empresas são aquelas que conseguiram obter concessóes dos governos estaduais ou do governo federal para recuperar e conservar trechos de rodovias. $\mathrm{O}$ segundo sub-bloco $\left(3^{B}\right)$ é o composto por empresas projetistas e por empresas de consultoria. Aparentemente trata-se de um grupo estratégico para o processo de inovação setorial. As firmas de projeto em geral atuam nas diversas regiōes do País, e às vezes também no exterior (predominantemente na América Latina e na África, em apoio aos seus clientes construtores rodoviários atuando nesses mercados). Elas possuem clientes tanto na área pública quanto na privada, pois atendem aos departamentos estaduais, e ao departamento nacional, responsáveis pelas estradas de rodagem, assim como às empresas concessionárias de rodovias. De forma similar, as empresas de consultoria, embora sendo empresas de menor porte comparadas às "projetistas", também atendem ao mesmo conjunto de clientes. O terceiro sub-bloco $\left(3^{\circ}\right)$ é o das firmas que se dedicam à construção e recuperação rodoviária. Estas empresas também estão fortemente enviesadas para o atendimento aos empreendimentos públicos: elas são em geral contratadas pelos órgãos públicos responsáveis pelas estradas de rodagem, visando à execução das atividades operacionais de construção e preservação de vias. Eventualmente elas atendem também demandas, da mesma natureza, das empresas concessionárias. Neste terceiro bloco, o quarto sub-bloco $\left(3^{D}\right)$ identificado é o referente às firmas fabricantes de máquinas e equipamentos para pavimentação 
rodoviária com asfalto, especialmente os fabricantes das usinas de asfalto, vibroacabadoras, rolos de compactação, e máquinas de fresa que são usadas na reciclagem de asfalto.

O quarto bloco ( $\mathbf{4}^{\mathbf{o}}$ bloco) de atores do setor é o composto pelas universidades. Este conjunto de atores no caso brasileiro aparentemente vem apresentando um interessante potencial de contribuição para as transformaçôes setoriais necessárias, seja na formação de recursos humanos para atuação na engenharia rodoviária nacional, ou pelas atividades de pesquisa e desenvolvimento, ora em curso na área de pavimentação. $\mathrm{O}$ quinto bloco ( $5^{\circ}$ bloco) é o dos institutos de pesquisa e desenvolvimento tecnológico. No caso do Brasil dois atores ficam evidenciados: o Instituto de Pesquisas Rodoviárias - IPR, do Departamento Nacional de Infraestrutura de Transportes - DNIT, e o Centro de Pesquisas da Petrobras - CENPES. Podem ser citados também o Instituto de Pesquisas Tecnológicas - IPT, do Estado de São Paulo, de atuação local, e o Centro de Tecnologia Mineral - CETEM, este último no âmbito federal, e com atuação junto aos produtores de agregados (britas usadas na produção do concreto asfáltico). O sexto bloco ( $\boldsymbol{6}^{\circ}$ bloco $)$ é o das autarquias e órgãos da administração direta. Essas organizações apresentam algumas especificidades importantes que as caracterizam. Uma dessas especificidades se refere à própria função desses órgãos governamentais, como responsáveis por gerir ou aplicar os investimentos públicos na construção e na preservação geral das vias rodoviárias. Tal responsabilidade desdobra-se nos três níveis governamentais - o federal, o estadual e o municipal.

Há um aspecto importante da problemática em foco que está estreitamente vinculado aos papéis dos atores do sexto bloco (DNIT, DERs, Secretarias e/ou Empresas Municipais de Obras). O DNIT é a organização criada após a extinção do Departamento Nacional de Estradas de Rodagem - DNER, porém também com responsabilidades sobre outros modais de transporte. Esses atores intermedeiam, por um lado, a demanda da sociedade pela infraestrutura rodoviária e, por outro, a oferta de bens, insumos e serviços de diferentes ramos industriais que atuam na construção e preservação das rodovias. Ou seja, os departamentos e secretarias de governo (autarquias) afeitas a esta atividade são os principais gestores dos sistemas de vias rodoviárias distribuídas no território nacional. Quando os departamentos estaduais de estradas de rodagem foram criados, no passado, eles atuavam diretamente nas operações de construção e manutenção das rodovias, pois inicialmente não havia firmas de construção disponíveis para tais serviços. Gradativamente tais funções operacionais foram sendo desativadas, estando hoje praticamente extintas. Esses departamentos agora se dedicam à contratação e fiscalização destes serviços, e estabelecem os critérios técnicos a serem praticados pelas firmas de projeto, e pelas firmas que realizam as obras.

Há certos atores que não estão presentes em nenhum destes seis blocos descritos. Eles podem ser considerados como sendo atores relativamente externos, ao setor. No entanto, estes agentes externos podem exercer, em determinados períodos, relevante influência na dinâmica setorial, relativamente ao processo de geração de inovaçōes. Essa influência pode ser no sentido tanto de promover transformaçōes, quanto de obstruí-las ou retardá-las. Um destes atores "externos" pode ser o próprio governo federal, por exemplo, através dos investimentos do PAC, o Programa de Aceleração do Crescimento, coordenado pelo Ministério da Casa Civil. Outro exemplo seria o Tribunal de Contas da União - TCU, nas suas auditorias e intervenções em obras deste mesmo PAC; outro exemplo, o Exército Brasileiro, auxiliando na construção de estradas estratégicas; ou a Confederação Nacional dos Transportes - CNT, avaliando anualmente o estado das rodovias; ainda pode-se apontar entre estes agentes externos, a Mídia, comunicando as expectativas da sociedade em relação à malha rodoviária (críticas, reportagens, etc.); outro ator é o Banco Nacional de Desenvolvimento Econômico e Social - BNDES, com eventuais programas de financiamento aos agentes do setor.

\section{RESULTADOS}

Abaixo são relatados os resultados da presente pesquisa segundo os tópicos preconizados pelo Projeto ESSY, adaptado às condiçóes locais.

\subsection{PAVIMENTAÇÃO: DEMANDA E PERFIL}

Qualquer setor industrial ou de serviços existe visando o atendimento a determinada demanda. As demandas sobre os setores tendem a variar com o tempo, exigindo, por parte destes, 
adaptações. A principal percepção hoje existente sobre o nível de adequação do modal rodoviário no Brasil é a pesquisa realizada anualmente pelo setor transportador. A CNT desde 1995 vem realizando pesquisa qualitativa sobre a situação rodoviária, contemplando as principais rodovias nas quais trafegam significativa parcela da produção agrícola e industrial brasileira.

A evolução da situação dessa malha ao longo da década dos anos 2000 sinaliza a dificuldade do setor em ofertar seu produto no nível qualitativo que lhe é demandado. Em 2010, o resultado geral da parcela pesquisada que apresentou como situação a característica "boa" ou "ótima", foi de $41,2 \%$, resultado inferior ao nível verificado entre 2003-2007. É necessário, no entanto, entender o critério desta avaliação. A situação geral das rodovias, a cada ano, é a composição das situações dos seus "pavimentos", "sinalizaçôes" e "geometrias". A situação dos pavimentos é de especial interesse ao presente estudo. A pesquisa CNT examina três variáveis dos pavimentos: ( $\left.1^{a}\right)$ condição da superfície; (2a) velocidade possível de praticar devido o pavimento; e ( $3^{a}$ ) estado do acostamento. A avaliação baseia-se na "ocorrência" ou "predominância" das evidências encontradas. A "ocorrência" de uma variável significa a presença de uma situação pontual, enquanto sua "predominância" significa incidência de determinado aspecto em mais da metade do trecho examinado (cada unidade de pesquisa é, no máximo, de dez quilômetros de rodovia).

Os 90.945 quilômetros analisados em 2010 corresponderam a $42 \%$ da malha rodoviária brasileira pavimentada, se for considerado que esta malha, segundo o Anuário Estatístico 2009 (referente aos dados do ano de 2008) era cerca de 218.000 quilômetros.

Em 2010, a "velocidade devido ao pavimento" e o "pavimento do acostamento" resultaram favoráveis: $89 \%$ dos acostamentos da extensão total pesquisada estavam pavimentados e perfeitos, e $97 \%$ da extensão pesquisada não exigiam redução da velocidade em função do pavimento. Quanto à superfície do pavimento, evidenciou-se que 39.935 quilômetros (43,9\% da extensão total) estavam perfeitos. Isso significa que existia adequada regularidade superficial no pavimento e não se percebia nenhum tipo de trepidação do veículo durante o deslocamento. Este exame da superfície do pavimento na metodologia de pesquisa da CNT usa por referências: o "Manual de
Identificação de Defeitos" - MID para revestimentos asfálticos; e a Norma 009/2003 - PRO. São documentos elaborados pelo DNIT, e estabelecem critérios de avaliação subjetiva de pavimentos, não pressupondo obrigatoriedade do uso de equipamentos de aferição, sendo, portanto, tal identificação feita segundo a percepção do usuário ao trafegar pela via. Já 51.010 quilômetros (correspondendo a 56,1\% da extensão pesquisada) necessitavam de algum tipo de intervenção na "superfície do pavimento". Havia 28.278 quilômetros (32,2\% da extensão) com o pavimento apresentando sinais de desgaste, conseguia-se perceber irregularidades superficiais, mas ainda não havia buracos. Outros 18.026 quilômetros (19,8\% da extensão) apresentavam trincas em malha ou remendos no pavimento, gerando trepidação no interior do veículo, mas ainda não havia presença de buracos. Evidenciou-se 18.026 quilômetros (3,2\% da extensão) apresentando afundamentos e (ou) ondulações causadas pela infiltração de água, ou causadas pela deflexão gerada pelo tráfego de veículos e (ou) por buracos. E havia 788 quilômetros $(0,9 \%$ da extensão) totalmente destruídos, ou seja, o pavimento apresentava elevada ocorrência de buracos ou ruína total, podendo obrigar à redução de velocidade do veículo. (CNT, 2010).

O Brasil apresenta defasagem negativa, entre 40 e $45 \%$, na sua pavimentação, ao compará-lo à média mundial e ao percentual da malha pavimentada dos EUA. Não significa isso afirmar que ao pavimentar as regiōes hoje com malhas rodoviárias mal estruturadas, os contrastes regionais serão automaticamente revertidos. No entanto, o exemplo próximo do estado de São Paulo, pela sua trajetória histórica ao longo do Século XX, e pelo desempenho regional que hoje apresenta, indica que a opção de garantir porte e qualidade ao referido modal, foi fator que significativamente contribuiu para o crescimento estadual. A malha rodoviária paulista favoreceu o Estado interligar e integrar suas regiōes, produzir e crescer. Existe, portanto, enorme potencial para promover investimentos na pavimentação regional, em todo País. Há, aí, especialmente ao computar as dimensões territoriais envolvidas no caso brasileiro, a possibilidade de ganhos de escala. Isso pode ser um facilitador para promover a eficiência da cadeia produtiva do setor brasileiro de pavimentação, como um todo.

Além da defasagem quantitativa, acima 
apontada, no nível atual de pavimentação brasileira em relação ao contexto internacional de referência, faz-se necessário, no caso local, especial atenção também ao aspecto qualitativo. Assim como ocorre no Exterior, internamente no País está havendo a passagem para configurações de tráfegos e cargas cada vez mais severos. As rodovias, adicionalmente, ainda são pouco fiscalizadas. A pesquisa identificou evidências de níveis de solicitação, pelos usuários brasileiros, mais intensos que os verificados na Europa e Estados Unidos. A tonelagem média anual, por quilômetro de rodovia, no Brasil, de 2.248. $\left(^{*}\right)$, sendo $\left(^{*}\right)=($ Toneladas . Km / Km . pavimentado), é bem superior à mesma taxa de utilização nos Estados Unidos, 296.(*), Japão, 319.(*), Alemanha, 342.(*), Reino Unido, 385.(*), França, 195.(*), Itália, 585. $\left(^{*}\right)$ e Espanha, 625.(*). (Schroeder, 1996). Outras evidências ainda indicam padrões de projetos que dimensionam as estruturas dos pavimentos aquém dos níveis de resistência necessários. Em termos locais, o dimensionamento da espessura de reforço $\left(\mathbf{H}_{\mathbf{r}}\right)$ em rodovias de tráfego pesado, nos casos que a espessura do revestimento " $h_{r}$ " é tal que $\mathbf{h}_{\mathbf{r}} \geq 10$ centímetros, vem sendo preconizado usando como deflexão admissível $\left(\boldsymbol{D}_{a d m}\right)$, aquela calculada por: $\log \left(D_{a d m}\right)=3,148-0,188 \cdot \log \left(N_{f}\right)$, (DNIT, 2006, p.159: Manual de Restauração de Pavimentos Asfálticos, sendo $N_{p}$ a "vida de fadiga”). Em tais circunstâncias tal deflexão deveria ser dimensionada por $\log \left(D_{a d m}\right)=3,479-0,289$. $\log \left(N_{p}\right)$. (Medina, 2005: "Mecânica dos Pavimentos"; UFRJ).

\subsection{CONHECIMENTO E APRENDIZADO}

Em termos acadêmicos, foi observado que já estão disponíveis no País significativos recursos e competências para pesquisas de campo e laboratoriais, e há relevante literatura técnica brasileira, atualizada, em engenharia de pavimentação. São resultados decorrentes da ação do Fundo Nacional de Desenvolvimento Científico e Tecnológico - FNDCT, Conselho Nacional de Pesquisa - CNPq, Coordenação de Aperfeiçoamento de Pessoal de Nível Superior - CAPES, Financiadora de Estudos e Projetos - FINEP e Fundações Estaduais de Amparo a Pesquisa, ao longo das últimas décadas. Essas competências nacionais referentes ao domínio científico e tecnológico do conhecimento em pavimentação asfáltica estão em processo de expansão regional (ação da rede específica, da Petrobras, no tema asfalto). Isso foi evidenciado no exemplo dos ativos intelectuais existentes na USP (seus laboratórios de mecânica dos pavimentos e de tecnologia da pavimentação), no Departamento de Engenharia de Transportes, e ativos similares existentes na Universidade Federal do Rio de Janeiro - UFRJ, Universidade Federal do Rio Grande do Sul - UFRGS e Universidade Federal do Ceará - UFC.

Sob o outro aspecto do conhecimento, no domínio da inteligência de campo, as firmas concessionárias vêm adotando e influenciando a adoção pelos demais agentes, dos asfaltos modificados por borracha ou por outros polímeros, como o Estireno Butadieno Estireno - SBS, e o Etileno Acetato de Vinila - EVA, que são classificados como elastômeros termoplásticos: em baixas temperaturas têm comportamento elástico e nas altas seu comportamento é termoplástico, constituindo-se ambos em fontes de inovações. Esses tipos de asfaltos apresentam maior resistência tanto à ocorrência de deformação permanente quanto à fadiga, sendo usados na Europa e nos EUA em intensidade maior que o consumo brasileiro. As distribuidoras prestam importante apoio na introdução dessas inovações com os modificados, e noutras relativas às emulsões, através de acompanhamento e assistência técnica. As condições cambiantes de utilização das vias, relativas aos esforços crescentes sobre os pavimentos, pressionam pela seleção e produção de asfaltos mais apropriados, que sejam mais duros, e obviamente pela adoção de projetos estruturais compatíveis com os presentes níveis de solicitação das cargas. Ao utilizar misturas com esses asfaltos mais resistentes, há necessidade também de adequar os equipamentos e os próprios parâmetros operacionais empregados. Faz-se necessário, entretanto, algumas adaptações operacionais, seja nos procedimentos com equipamentos de pavimentação, seja nas usinas de asfalto. No ponto de vista dos fabricantes das usinas e equipamentos, há que se investir, sistematicamente, na capacitação de pessoal, especializando operadores para usinas automatizadas, pois para estas, as habilidades e conhecimentos necessários à operação das usinas tradicionais não são suficientes. Mesmo nas usinas tradicionais em operação no Brasil, para os fabricantes, há evidências de que é preciso se estabelecer um maior nível de qualificação dos operadores. 
6.3 EMPRESAS, ORGANIZAÇÕES NÃO-EMPRESARIAIS, REDES E "INSTITUIÇÕES"

Neste Setor, as firmas podem ter diferentes funçôes: há uma petrolífera (com suas refinarias produtoras de asfaltos) e as distribuidoras (produção de asfaltos modificados e emulsões asfálticas) que exercem papéis estreitamente vinculados; e o outro conjunto de firmas (concessionárias, projetistas/consultoras, empreiteiras e fabricantes de usinas e máquinas de pavimentação) que exerce papel central na construção e conservação dos pavimentos rodoviários.

Este segundo grupo de firmas (citado anteriormente como " 3 o bloco") representa as firmas com funçôes complementares, desde a elaboração do projeto até a execução final da pavimentação, além da gestão e conservação de rodovias concedidas, e a fabricação e fornecimento de usinas, máquinas e equipamentos. São firmas, em maior ou menor grau, que absorvem conhecimento para produzir e inovar serviços e bens para o modal, conforme suas habilidades acumuladas no tempo. As firmas empreiteiras sofreram os efeitos nefastos das rupturas e descontinuidades da demanda, ocorridas nas décadas de 1980 e 1990 . O fortalecimento e acúmulo de suas competências foram obstruídos, em conseqüência das incertezas originadas a partir de períodos de inadimplência dos órgãos públicos com as mesmas. Essas firmas conseqüentemente enfrentaram dificuldades na capacitação e retenção de pessoal qualificado, e por decorrência, dificuldades no controle tecnológico das suas operaçôes nas usinas de asfalto e nas obras. Paralelamente, houve redução das suas iniciativas para renovação do maquinário (usinas de asfalto e vibroacabadoras), além de se buscar especificá-lo no sentido de reduzir o custo final de aquisição, via simplificações que gradativamente afastaram o fornecimento local do padrão praticado pelos fabricantes nos fornecimentos voltados para a exportação. Esse conjunto de adversidades implicou em queda do desempenho dos serviços e em redução da sua capacidade de perceber e promover as inovações necessárias.

Cabe observar que o papel das autarquias e dos órgãos da administração direta tem relevante influência no processo de aprendizado destas firmas (ou "daquilo" que elas efetivamente produzem, aprendem e inovam). Estes "atores" (anterior- mente citados como " 6 o bloco") definem, aprovam ou validam os projetos e as práticas de execução, através de contratos e posterior fiscalização. Daí resulta o tipo de pavimentação que é de fato realizada. Se esses órgãos e autarquias são capacitados e fortalecidos em seus papéis, a probabilidade de resultados satisfatórios, tais como produção com qualidade, aprendizado acumulado e inovação, pelos três conjuntos de firmas $\left(1^{\circ}, 2^{\circ}\right.$ e $3^{\circ}$ blocos $)$ será maior, caso contrário, provavelmente menor. A situação configurada, no entanto, é de enfraquecimento destes órgãos, com sinais recentes de reversão do quadro vigente a partir de 2005.

Há várias práticas institucionais - formais e informais - importantes na operação geral do Setor. Além dos aspectos acima mencionados (funções e disfunções das autarquias), cabe apontar os agentes que formulam e aprovam: especificações de asfalto (Instituto Brasileiro de Asfalto - IBP; Associação Brasileira de Normas Técnicas - ABNT; Agência do Petróleo, Gás e Biocombustíveis - ANP); métodos de ensaio e especificações de serviços para obras rodoviárias (DNIT, coordenadas pelo seu Instituto de Pesquisas Rodoviárias, que preserva também o acervo gerado pelo antigo DNER); os que adaptam e adotam tais normas (Departamentos Estaduais de Estradas de Rodagem, Secretarias Municipais de Obras, ou as Empresas Municipais de Obras em alguns casos). Cabe observar se são adequadas ou não, e o uso prático dessas especificações e métodos, no âmbito das obras e das atividades conduzidas pelos agentes públicos federais, estaduais, municipais, e pelos agentes privados, as construtoras e concessionárias já descritas. Outra faceta setorial a considerar é a ação investigatória do Tribunal de Contas da União referente às licitações e às obras rodoviárias em andamento, e ações de intervenção dele sobre as mesmas, com eventuais ou freqüentes paralisações de obras. No que tange ao balanço entre o custo e o benefício, obviamente não há que se questionar o mérito das investigaçóes: cabe ao TCU legitimamente investigar qualquer indício de irregularidade. Mas, também de forma legítima, há questionamentos em curso por diversos agentes setoriais (firmas, DNIT, e o próprio Governo Federal) sobre os métodos e critérios praticados, e principalmente quanto aos efeitos prejudiciais dessas ações do TCU à sociedade, quando geram a descontinuidade de obras em empreendimentos relevantes. 
Há também outros tipos relevantes de ações institucionais, como os programas de fomento à pesquisa científica e tecnológica e à inovação: os programas da FINEP, como as redes cooperativas no âmbito do fundo setorial de financiamento de ciência e tecnologia para o setor petrolífero (CT-Petro), operacionalizado pela FINEP com apoio da ANP, e que utiliza metodologias iniciadas pelo Programa de Desenvolvimento das Engenharias PRODENGE; e os instrumentos de financiamento do BNDES, gerais ou específicos, servindo ao setor de pavimentação rodoviária.

Outros agentes são os próprios usuários das vias, com demandas refletidas nas avaliações anuais sobre a condição da malha rodoviária nacional, feitas pela CNT, e os desdobramentos e efeitos individuais e coletivos dessas avaliaçōes. Alguns agentes setoriais descritos nos agrupamentos (blocos) anteriores adicionalmente se unem através de coalizões, parcerias, etc. Estas associações podem ocorrer entre agentes similares, como a ABEDA anteriormente citada, ou entre agentes heterogêneos, como a Associação Brasileira de Pavimentação - ABPv. A ABEDA, a Associação Brasileira de Concessionárias de Rodovias - ABCR, a Associação Nacional de Empresas de Obras Rodoviárias - ANEOR atuam de forma similar, visando politicamente defender os interesses das suas firmas. Algumas iniciativas e articulações destas associações vêm influenciando na adoção gradativa de asfaltos mais resistentes no País. Associações entre agentes não similares, como a ABPV e a Comissão de Asfalto do IBP, por outro lado, através de cursos, eventos, grupos de trabalho, etc., vêm desempenhando função relevante na interação setorial. Há também convergências de atores: as reuniôes da Associação Brasileira dos Departamentos de Estradas de Rodagem - ABDER; e as reuniōes e workshops de avaliação anual da produção de asfalto, promovidos pela Petrobras, contando com a participação de representantes de autarquias federais, estaduais, municipais, associações, empresas e universidades.

\subsection{DINÂMICA SETORIAL E COEVOLUÇÃO}

Ao longo das décadas de 1990 e 2000, relativamente às pesquisas em pavimentação com asfalto, foi possível se estruturar, científica e tecnologicamente, significativo número de univer- sidades brasileiras. Atualmente elas dispõem dos meios necessários às suas atividades laboratoriais, e promovem pesquisas ao nível do que está sendo realizado nos países mais desenvolvidos. Isso em parte foi reforçado pelo suporte financeiro e empresarial da petrolífera estatal brasileira - a Petrobras - iniciado nos anos 80 e 90 , e especialmente na década dos anos 2000. Este apoio ao setor de pavimentação foi traduzido: em contratos tradicionais para pesquisas, na criação do CEASF, o Centro de Excelência em Asfalto (o projeto estratégico da Petrobras para desenvolvimento dos chamados Centros e Redes de Excelência buscava agregar empresas, órgãos governamentais, universidades, institutos de pesquisa para ações empresarias, institucionais, tecnológicas e científicas em torno de temas relevantes, considerados como de interesse para o conjunto de atores envolvidos o tema "asfalto" foi um dos temas desenvolvidos no Projeto), em aplicaçōes de recursos do Fundo Setorial do Petróleo e Gás - CT-Petro, em aplicaçôes dos recursos das "Participaçōes Especiais" (parcela dos royaltes referentes aos campos petrolíferos de alta produção, usados para a criação e desenvolvimento de redes temáticas de pesquisa cooperativa, entre elas a "Rede Temática de Asfalto"), no programa "Proasfalto" para capacitação de professores da graduação, para fortalecimento das disciplinas de pavimentação nas universidades brasileiras, financiado e apoiado pela Petrobras em parceria com a Associação Brasileira de Empresas Distribuidoras de Asfalto - ABEDA, e elaborado pelos professores da USP, UFRJ, UFRGS e UFC, e na criação do "Instituto Pavimentar" (o Instituto Pavimentar é um programa de treinamento da Petrobras, também em parceria com a ABE$\mathrm{DA}$, direcionado à qualificação técnica do pessoal envolvido com as operaçôes das usinas de asfalto e das máquinas e equipamentos de pavimentação).

$\mathrm{O}$ aspecto singular, nesse particular, é que o apoio da Petrobras embora importante, teve papel parcial, não cobrindo importantes lacunas existentes no contexto institucional do Setor. Em países desenvolvidos, tal apoio é predominantemente dado pelos próprios órgãos rodoviários governamentais, o que facilita incorporar conhecimento (difusão das inovações) em tais órgãos, e conseqüentemente nas firmas que lhes fornecem bens e serviços.

O DNIT e os DERs, portanto, seriam os principais clientes das citadas pesquisas. Mas no 
contexto setorial atual, eles não se equivalem, em termos do processo de inovação e nas interações científicas e tecnológicas com universidades locais, ao papel dos seus congêneres internacionais. Agentes acadêmicos que atuam no setor demonstram preocupações quanto à manutenção e contínuo fortalecimento dos grupos de pesquisa (Soares, 2009). Ou seja, diferentemente do que ocorre no Brasil, nos países desenvolvidos tais grupos são suportados principalmente com financiamentos oriundos de entidades que corresponderiam aos departamentos brasileiros, federais ou estaduais, responsáveis pela infra-estrutura rodoviária: equivalentes aos DNIT e DERs. As várias iniciativas conduzidas pela Petrobras (financiamentos de P\&D, Ceasf, Proasfalto, Instituto Pavimentar, Rede Temática, etc.) indubitavelmente auxiliaram a pavimentação rodoviária nacional, e amenizaram em parte os efeitos adversos sofridos pelo setor nas últimas décadas. $\mathrm{O}$ desmonte do setor público nos anos 80 induziu o que se poderia chamar de "coevolução não virtuosa" dos condicionantes produtivos: desatualização dos padrões técnicos, desmobilização das firmas empreiteiras e seus profissionais, distanciamento destes órgãos das atividades de cooperação técnica com pesquisadores dos laboratórios das universidades. Entretanto o fato novo, de natureza intensamente transformadora, que ressalta setorialmente, é o advento do Programa de Aceleração do Crescimento. Sob a ótica petrolífera, a maior evidência do potencial e efetividade do PAC foi se elevar o consumo de asfalto no País, próximo a $1,5 \mathrm{mi}$ lhôes em 2005, para cerca de 3,0 milhões de toneladas anuais, em 2010.

Na década de 1960 um empreendedor local, empreiteiro, no Rio Grande do Sul, construiu a primeira usina brasileira do tipo conhecido como "gravimétrica". Ele fundou então uma firma para explorar esse mercado, e passou a concorrer com a empresa estadunidense Barber-Greene, que havia se instalado em São Paulo. Em parceria com a Mitsubishi Heavy Industries, parceria que duraria pouco tempo, a firma local iniciou a fabricar também vibroacabadoras. Nos anos 80 a firma gaúcha foi adquirida por empresários alemães, tornando-se a CIBER Equipamentos Rodoviários. Ainda nessa década de 1980 o mesmo empreendedor criou uma nova empresa, denominada CIFALI, que construiu, no País, as usinas do tipo "a tambor”, além de introduzir tecnologias então recen- tes, como as usinas de asfalto montadas sobre um único chassi. Estas últimas permitiam maior mobilidade, e eram dotadas de sistema de automação, além de processo de filtragem, por filtro de mangas. Em 2000 a então CIFALI foi adquirida por outra multinacional, desta feita norte-americana, a TEREX. Na década de 2000 surgiria um terceiro fabricante na região, a TICEL, liderada por antigos funcionários da CIFALI. Inicialmente eles apenas reformavam antigas usinas de asfalto, mas as oportunidades então disponíveis (encomendas e oferta de capital pelos próprios clientes) fizeram que fundassem essa empresa e, gradativamente, iniciassem seu processo de crescimento e exportação de equipamentos (fonte: relato direto do empreendedor, a um dos autores, em visita às instalações da TICEL em 2008). Foi possível constatar durante as reuniōes com os fabricantes, em 2008, haver significativa mobilidade de profissionais entre essas três empresas, (CIBER, TEREX e TICEL). A capacidade de criar e recriar empresas fabricantes de usinas de asfalto e vibroacabadoras, no Rio Grande do Sul, indica que existe relevante capacidade de retenção dessas competências no âmbito regional. Essas empresas, especialmente as duas mais antigas, estabeleceram uma vasta rede de distribuidores e de assistência técnica (fornecimento de itens de reposição) nas várias regiōes do País: a dinâmica industrial neste segmento, entre os municípios gaúchos de Canoas e Caxias de Sul, inclusive já habituado a exportar para a África e América Latina parte da sua produção, gerou um verdadeiro aglomerado de competências, traduzido na produção e inovação deste tipo de maquinário.

\subsection{POLÍTICAS PÚBLICAS}

O caso da pavimentação aponta para inequívoca importância do papel das políticas públicas, pois a despeito do paulatino crescimento das concessões rodoviárias, a orientação de investimentos para esse modal, assim como para os demais modais de transporte, mesmo nos países já desenvolvidos, historicamente conta com a função central exercida por tais políticas.

É notório que no País, por fatores institucionais e históricos, o setor rodoviário prepondera como principal modal no transporte de cargas. As questôes centrais relativas às políticas públicas, em transportes, hoje envolvem as seguintes 
vertentes: a recuperação e adequação da malha existente (açôes ora em curso impulsionadas pelo PAC); a expansão da malha (os investimentos hoje necessários à recuperação inibem investir na rápida expansão das malhas regionais); a mudança da matriz dos transportes (planejada no Plano Nacional de Logística de Transporte - PNLT, elaborado pelo Centro de Excelência em Transporte - CENTRAN, e já em curso inicial com a parcela dos recursos do PAC hoje direcionada para os demais modais, especialmente para o ferroviário e hidroviário) - sendo provável que o estabelecimento de uma matriz mais equilibrada corrija fenômenos identificados na pesquisa, como intensidade excessiva de utilização, e sobrecarregas, nas principais rodovias. Cumpre salientar que os órgãos públicos encarregados da execução das políticas governamentais estão sujeitos às pressões de interesses privados escusos. Cabe especial atenção no sentido de fortalecê-los em suas atribuições, e resguardá-los de possíveis desvios.

Evidências documentais recentes apontam diversos instrumentos do BNDES para apoio à recuperação e expansão da malha rodoviária, entre 2005 e 2010: [1] Revista Portuária, publicado em 06/06/2008: “BNDES financia com $\boldsymbol{R} \$ 174$ milhóes investimentos em rodovias em SP'. [2] Site do BNDES, postado em 13/10/2009 (acesso eletrônico em 23/06/2010): "BNDES e IFC apóiam expansão de rodovias federais". [3] Valor Online, postado em 14/05/2009 (acesso eletrônico em 26/06/2010): “OHL receberá $R$ \$ 756 milhóes do BNDES para investir em rodovias". O Banco tem financiado empresas concessionárias vencedoras de licitações de importantes trechos rodoviários federais e estaduais. Ele abriu, por exemplo, no período acima citado, uma linha de crédito para pequenos e médios municípios adquirirem equipamentos de pavimentação rodoviária. Este programa é denominado de "PROVIAS”: [4] Site do BNDES (www.bndespar.gov. br; acesso eletrônico em 23/06/2010): "Programa de Intervençóes Viárias - PROVIAS, do $B N D E S^{\circ}$. Para as empresas de construção civil, grupo esse no qual se enquadram as empreiteiras que atendem ao DNIT, aos DERs e às Prefeituras, há agora todo um conjunto de linhas de financiamento envolvendo: a aquisição de equipamentos usados fabricados no País (usinas de asfalto, vibroacabadoras, veículos para operaçôes de compactação de solos, etc.), o tradicional financiamento de máquinas e equipamentos novos, financiamento à inovação, inclusive à estruturação de centros de pesquisa empresariais, e financiamento à capacidade produtiva, (BNDES, 2009).

No plano científico e tecnológico, e da educação superior, o cenário é satisfatório comparativamente aos padrōes internacionais. Entretanto, o pleno aproveitamento do conhecimento e potencial de inovação que emergem da academia hoje é constrangido e influenciado pelos efeitos negativos decorrentes do enfraquecimento financeiro, operacional e técnico ocorrido nos órgãos rodoviários públicos. Portanto, torna-se necessário, para coevolução de todo o setor, resgatar o pleno papel institucional destes órgãos, além de fortalecer-lhes as capacitações, e estimular que se integrem com as universidades.

\subsection{FRONTEIRAS GEOGRÁFICAS}

O enfoque dado às fronteiras geográficas na investigação abordou, inicialmente, as diferenças perceptíveis entre regiōes brasileiras, e as diferenças especificamente estaduais, quanto ao desempenho da pavimentação. A comparação, com dados do DNIT, mostrou vantagem logística no modal rodoviário para os Estados de São Paulo, Rio Grande do Sul, Rio de Janeiro, Minas Gerais e Paraná. Isso evidencia haver neles maior potencial, atualmente, para ampliação do desenvolvimento econômico regional. Por outro lado, estudo referente às décadas de 1970 e 1980, e a primeira metade da década de 1990, evidenciou a retomada da competitividade da área industrial tradicional, com São Paulo revertendo uma tendência declinante à concentração, observada até 1985, e também Minas Gerais, destacando-se esses dois estados com os melhores níveis de competitividade para atração de empresas, entre as cinco regiōes analisadas. As regiōes analisadas quanto ao nível de concentração industrial foram: Região Nordeste, Região Sul e os estados de Minas Gerais, São Paulo e Rio de Janeiro. Os indicadores apontaram que a área industrial tradicional do país estava recuperando sua qualificação regional para receber novos investimentos, tanto em novas unidades industriais quanto para o aumento da produção nas unidades nela já existentes. Além da reconcentração identificada entre 1985 e 1995 , esse estudo apontou para uma concentração ainda maior no futuro, em favor desta mesma região. Isso se deve a que as empresas essencialmente buscam 
locais em que o chamado "salário de eficiência" é baixo, mesmo que os chamados "salários nominais" sejam altos - a produtividade compensará o maior nível salarial. A produtividade varia entre regióes devido às economias de aglomeração, sendo que as variações salariais entre regiôes, determinadas pelas ofertas e demandas de trabalho, pouco oscilam, e por isso os salários nominais não preponderam na escolha que empreendedores fazem em onde vão instalar suas novas fábricas, comparativamente às variaçôes que ocorrem na produtividade. (Azzoni e Ferreira; 1998).

São Paulo entre todos os estados brasileiros é detentor da maior extensão pavimentada. São Paulo, Rio Grande do Sul, Rio de Janeiro, Minas Gerais e Paraná representam importantes referenciais para aos demais Estados. As interações cooperativas entre os setores regionais de pavimentação rodoviária - de natureza comercial, operacional e técnica - entre estas cinco unidades da federação, e as demais, podem favorecer a evolução das regiōes hoje logística e economicamente defasadas.

Em complemento aos aspectos regionais brasileiros, há outro, de cunho estratégico a considerar, que é o interesse brasileiro na integração econômica sulamericana. Para tanto, avultam de importância as ligações rodoviárias. Cabe ressaltar a iniciativa em curso, desde 2000, para a Integração da Infraestrutura Regional Sulamericana - IIRSA, envolvendo doze países do continente (Argentina, Bolívia, Brasil, Chile, Colômbia, Equador, Guyana, Paraguay, Peru, Suriname, Uruguay, Venezuela), na qual importantes trechos rodoviários deverão ser disponibilizados. Evidentemente, o Brasil tem um importante papel a desempenhar nessa integração, pelo porte das suas principais empresas construtoras e pela sua infraestrutura científica e tecnológica.

\subsection{DESEMPENHO INTERNACIONAL}

A aplicação do método ESSY na comparação do desempenho da pavimentação local com a internacional visou identificar os fatores que permitiriam ou facilitariam o alcance, pelo Brasil, do nível de pavimentação qualitativo e quantitativo já estabelecido seja na Europa, seja nos EUA, e melhor entender como as práticas locais hoje impedem se alcançar tal nível.

Adicionalmente, tendo por base o crescente grau de atuação internacional em rodovias por empresas brasileiras como Odebrecht, Queiroz Galvão, etc., as experiências por elas adquiridas nestes mercados externos provavelmente contribuirão no aprimoramento dessas práticas locais. Há firmas nacionais construindo estradas em Angola (Odebrecht, Queiroz Galvão, etc.), e operando concessões rodoviárias em Portugal (Odebrecht). A Odebrecht, por exemplo, após cinco anos de obras concluiu a pavimentação de todos $710 \mathrm{~km}$ dos trechos no-2 e no-3 da Rodovia Interoceânica Sul (IIRSA Sul), em dezembro de 2010: a inovação foi que a firma brasileira, líder do consórcio construtor, investiu com os parceiros US\$ 1 bilhão nesses trechos em troca de 25 anos de direito de concessão - estas obras são parte de um "corredor" de 1,5 mil quilômetros de rodovias que está sendo criado entre a fronteira do Brasil e do Peru (fonte: Valor Econômico, 05/05/2009; e www.odebrecht.com, acessado em, 15/06/2011).

Os dados mais recentes apontam que o Brasil em 2007 possuía 1.765.278 Km de rodovias, com extensão pavimentada de $211.678 \mathrm{Km}$ (cerca de $12 \%$, contra os $55 \%$ da média mundial e os $55 \%$ de pavimentação nos EUA). Identificou-se que a qualidade da malha rodoviária brasileira quando avaliada comparativamente no conjunto dos 139 países escrutinados na pesquisa do Global Competitive Report, situa-se muito aquém dos padrões técnicos praticados na Europa e nos EUA. Entre 2009 e 2010, o posicionamento relativo entre os países foi o seguinte: $1^{\circ}$, Singapura; $2^{\circ}$, França; $3^{\circ}$ Suíça; 4․ Hong Kong; 5ª Alemanha; $6^{\circ}$, Emirados Árabes Unidos; 70 , Áustria; 8º, Portugal; 9o, Dinamarca; $12^{\circ}$, Chile; $13^{\circ}$, Finlândia; $17^{\circ}$, Canadá; $18^{\circ}$, Suécia; $19^{\circ}$, Estados Unidos; tendo o Brasil ficado na $105^{a}$ posição. (World Economic Fórum, 2011: p.389).

Embora tal resultado indubitavelmente seja desconfortável, em contrapartida ele valoriza a importância de estudos adicionais e detalhamentos voltados às comparaçōes técnicas, econômicas e gerenciais, com estes referenciais. Quais são os insumos lá usados, e como são aplicados? Quais são os critérios e os padrōes de dimensionamento lá praticados? Qual o nível lá existente de qualificação profissional? Como se realiza esta qualificação? Qual é o padrão das usinas e maquinário lá usado? Referenciais como a França, Suíça, Alemanha, Áustria, Dinamarca, Portugal, e Estados Unidos podem fornecer valiosas informações 
para a evolução do setor local. Há asfaltos, portanto, que são mais resistentes que os tradicionais CAP.50/70 e CAP.30/45 usados no Brasil, porém que ainda não foram aqui adotados, correspondentes às faixas de penetração 10/20, 15/25, e 20/30. A adoção destes asfaltos é parte necessária à evolução dos padrôes de projeto e insumos dos pavimentos, no sentido de elevada resistência, a exemplo daqueles hoje encontrados na França. A França, 2a na colocação acima, a partir do final da 2a Grande Guerra promoveu uma série de inovaçõos na sua pavimentação. Já nos anos 80 o processo de aprimoramento das misturas asfálticas francesas levou ao desenvolvimento dos revestimentos de módulo elevado, a saber: a mistura asfáltica de módulo elevado usada como camada de ligação ou como base; e o concreto betuminoso de módulo elevado, usado essencialmente como camada de rolamento.

\section{CONCLUSÔES}

Evidências positivas apontam para a existência de um sistema setorial de inovação e produção em pavimentação com asfalto no Brasil, porém apresentando algumas lacunas e disfunções.

Como evidências positivas destacam-se: (1) a disponibilidade e o envolvimento de significativa infraestrutura acadêmica; (2) a existência de fabricantes de maquinário setorial que são inclusive exportadores; (3) as ações de inovação pelas concessionárias; (4) as importantes ações por parte da Petrobras nas articulações institucionais e nos aportes financeiros para P\&D; (5) a presença de grandes construtoras locais que são exportadoras de serviços, através de suas filiais na América do Sul, África e Europa; (6) significativas contribuições por parte das agências públicas de financiamento; (7) atuação das associações empresariais e não empresariais, intensificando a interação entre os diversos agentes, e atuando politicamente junto aos órgãos públicos e à Petrobras.

Evidências negativas que impedem o pleno funcionamento do sistema são: (1) desmonte dos órgãos rodoviários governamentais federais e estaduais; (2) reflexos da falta de investimentos nos anos 80 e 90, com o enfraquecimento dos demais atores; (3) falta de ação indutora por parte dos governos visando à inovação e o aumento de produtividade (lacuna parcialmente ocupada pela Petrobras); e (4) não exigência de padrões de di- mensionamento compatíveis com o estado da arte nos países desenvolvidos.

Em termos de recomendações sugere-se: (A) preservação e o fortalecimento dos órgãos rodoviários governamentais; (B) intensificar a ação destes órgãos rodoviários na promoção da pesquisa científica e tecnológica visando a inovação; (C) continuidade e intensificação dos investimentos governamentais, a exemplo do PAC e dos programas do BNDES associados; (D) aperfeiçoamento das ações do TCU no sentido de evitar prejuízos desnecessários ao modal.

\section{BIBLIOGRAFIA}

AMABLE, Bruno (2001). Les systèmes de innovation. CEPREMAP, Juin 2001. Contribution à l'Encyclopédie de l'innovation dirigée par Philippe Mustar et Hervé Penan.

AZZONI, C. R.; 1998. Competitividade regional e reconcentração industrial: o futuro das desigualdades regionais no Brasil. FEA/USP.

BARTHOLOMEU, D.B.; 2006. Quantificação dos impactos econômicos e ambientais decorrentes do estado de conservação das rodovias brasileiras. Tese (Doutorado) - Universidade de São Paulo, Escola Superior de Agricultura Luiz de Queiroz, Piracicaba, 2006. 159p.

BERNUCCI L.B., et al; 2008: Pavimentação asfáltica.

BNDES, 2009. "Apoio à Construção Civil". Cartilha explicativa organizada pelo Departamento de Programas e Políticas do BNDES, publicada em setembro de 2009.

BRACZYK, H-J, P. COOKE \& M. HEIDENREICH (eds.) (1998). Regional innovation systems: the role of governance in a globalized world. London and Pennsylvania: UCL.

BRESCHI, S. \& F. Malerba (1997). Sectoral innovation systems: technological regimes, Schumpeterian dynamics, and spatial boundaries. In Edquist, C. (ed.) 1997 Systems of Innovation: Technologies, Institutions and Organizations. London and Washington: Pinter/Cassell Academic. 
CARLSSON, B. (ed.) (1995). Technological systems and economic performance: the case of factory automation. Dordrecht: Kluwer.

CNT, 2010. Pesquisa CNT (Confederação Nacional dos Transportes) de Rodovias, 2010.

COOKE, P. Forthcoming (2000). Regional Innovation Systems, Clusters and the Knowledge Economy. Industrial \& Corporate Change, forthcoming 2000.

COOKE, P., Gomez Uranga, M. and Etxebarria, G. (1997) "Regional systems of Innovation: Institutional and Organisational Dimensions", Research Policy, 26, 1997: 475 - 491.

COWAN, R., DAVID, P., FORAY, D., 2000. The explicit economics of knowledge codification and tacitness. Industrial and Corporate Change, 9 (2), 211-253.

DNER, 1979. Avaliação estrutural dos pavimentos flexíveis. DNER-PRO 011/79, aprovado em 29.01.1979.

DNER, 1981. Método de Projeto de Pavimentos Flexíveis. Eng . Murillo de Souza; $3^{\text {a }}$ Edição; IPR, Rio de Janeiro.

DNIT, 2006: Manual de Restauração de Pavimentos Asfálticos.

DNIT, 2008. Anuário Estatístico dos Transportes Terrestres, 2008.

DOSI, G., 1997. Opportunities, incentives and the collective patterns of technological change. Economic Journal 107, 1530-1547.

DOSI, G., FREEMAN, C., NELSON,R.R., SILVERBERG, G., SOETE, L. (Eds), 1988: Technological Change and Economic Theory; Pinter, London.

EDQUIST C. (1997) 'Systems of innovation approaches - their emergence and characteristics' in Edquist, C. (ed.) (1997) Systems of Innovation: Technologies, Institutions and Organizations, London: Pinter/Cassell.
EDQUIST, C. and JOHNSON, B. (1997). 'Institutions and organisations in systems of innovation', in C. Edquist (ed.) Systems of Innovation: Technologies, Institutions and Organizations.

FREEMAN, C. (1987). Technology policy and economic performance: lessons from Japan. London: Pinter.

FREEMAN, Chris 1995: The 'National System of Innovation' in historical perspective; Cambridge Journal of Economics 1995, 19, 5-24. London and Washington: Pinter/Cassell Academic.

LONGO, 2007: Alguns impactos sociais do desenvolvimento científico e tecnológico. DataGramaZero - Revista de Ciência da Informação v. 8 n. 1 fev/07.

LUNDVALL, B.A., JOHNSON, B., 1994. The learning economy. Journal of Industry Studies 1 (2), 23-42.

LUNDVALL, B-A., 1992 (ed.). National Systems of Innovation: Towards a Theory of Innovation and Interactive learning, London: Pinter.

LUNDVALL., Bengt-Åke 2002 ; Björn Johnson; Esben Sloth Andersen; Bent Dalum; National systems of production, innovation and competence building; Research Policy 31 (2002) 213-231.

MALERBA, F., 2002: Sectoral systems in Europe - innovation, competitiveness and growth (ESSY); ESSY Final Report; under the fourth research and technological framework programme, targeted socio-economic research, TSER; Milan, Italy, $28^{\text {th }}$ February, 2002.

MALERBA, F., 2002b: ESSY Final Report; Milan, Italy, $28^{\text {th }}$ February 2002.

MALERBA, F., 2003: "Sectoral systems: how and why innovation differs across sectors"; Milan, October 13, 2003; for "Handbook of innovation", J. Fagerberg - D. Mowery - R. Nelson editors.

MEDINA, J., Motta, L., 2005: Mecânica dos Pavimentos; UFRJ. 
METCALFE, S., 1998. Evolutionary Economics and Creative Destruction. Routledge $\& \mathrm{Ke}-$ gan Paul, London.

NELSON R.; ROSEMBERG N. (1993) - “Technical innovation and national systems", in Nelson R. (ed), National Innovation Systems, Oxford University Press, Oxford.

NELSON, R. R. (1993) (ed.). National Innovation Systems: A Comparative Study, Oxford: Oxford University Press.

NELSON, R., 1995. Recent evolutionary theorizing about economic change. Journal of Economic Literature 33, 48-90.

NELSON, R.R., and MOWERY, D. (1999) (eds.) Sources of Industrial Leadership: Studies of Seven Industries, Cambridge: Cambridge University Press.

OLIVEIRA, A.R.P., 1999: Criação e centros e redes de excelência - estudo do caso Petrobras. Tese de Mestrado. Escola de Engenharia da Universidade Federal Fluminense. Outubro de 1999.
PÊGO FILHO et al.; 1999. Investimento e Financiamento da Infra-Estrutura no Brasil: 1990/2002. IPEA, texto para discussão, $\mathrm{N}^{\mathrm{O}} 680$.

PNLT, 2007: Plano Nacional de Logística de Transportes; Junho de 2007.

REVISTA VEJA, de Abril de 1989. "Estradas em ruínas - abandonados os 65.000 quilômetros de rodovias federais são vítimas de um feroz processo de destruição".

SCHROEDER E.M., Castro, J.C.; 1996: Revista do BNDES, Rio de janeiro, 1996.

SOARES, 2009. Asfalto em Revista, Ano-I, n.7, Set/Out-2009. Entrevista, Professor Jorge Barbosa Soares (Laboratório de Mecânica dos Pavimentos da Universidade Federal do Ceará).

WORLD ECONOMIC FORUM, 2009: The Global Competitiveness Report 2010-2011. 